\title{
Self Organising Wayfinding Support for Lifelong Learners
}

Citation for published version (APA):

Tattersall, C., Manderveld, J., Van den Berg, B., Van Es, R., Janssen, J., \& Koper, R. (2005). Self Organising Wayfinding Support for Lifelong Learners. Education and Information Technologies, 10(1), 111-123.

https://doi.org/10.1007/s10639-005-6750-9

DOI:

$10.1007 / \mathrm{s} 10639-005-6750-9$

Document status and date:

Published: 01/01/2005

Document Version:

Early version, also known as pre-print

Please check the document version of this publication:

- A submitted manuscript is the version of the article upon submission and before peer-review. There can be important differences between the submitted version and the official published version of record. People interested in the research are advised to contact the author for the final version of the publication, or visit the DOI to the publisher's website.

- The final author version and the galley proof are versions of the publication after peer review.

- The final published version features the final layout of the paper including the volume, issue and page numbers.

Link to publication

\section{General rights}

Copyright and moral rights for the publications made accessible in the public portal are retained by the authors and/or other copyright owners and it is a condition of accessing publications that users recognise and abide by the legal requirements associated with these rights.

- Users may download and print one copy of any publication from the public portal for the purpose of private study or research.

- You may not further distribute the material or use it for any profit-making activity or commercial gain

- You may freely distribute the URL identifying the publication in the public portal.

If the publication is distributed under the terms of Article 25fa of the Dutch Copyright Act, indicated by the "Taverne" license above, please follow below link for the End User Agreement:

https://www.ou.nl/taverne-agreement

Take down policy

If you believe that this document breaches copyright please contact us at:

pure-support@ou.nl

providing details and we will investigate your claim.

Downloaded from https://research.ou.nl/ on date: 26 Apr. 2023 
PRE-PRINT:

Correspondence concerning the article should be addressed to Colin Tattersall, Educational Technology Expertise Centre, Open University of the Netherlands, Valkenburgerweg 177, 6419 AT Heerlen, The Netherlands, Email: colin.tattersall@ou.nl, Fax: +3145 5762907

\title{
Self Organising Wayfinding Support for Lifelong Learners
}

\author{
Colin Tattersall, Jocelyn Manderveld, Bert van den Berg, René van Es, José Janssen, Rob Koper \\ Educational Technology Expertise Centre, Open University of the Netherlands, Valkenburgerweg \\ 177, 6419 AT Heerlen, The Netherlands
}

\begin{abstract}
Lifelong learning puts learner self-direction centre-stage. However, increased responsibility should not come at the price of over-burdening or abandonment of learners as they progress along their learning journey. This paper introduces an approach to wayfinding support for lifelong learners based on selforganisation theory. It describes an architecture which supports the recording, processing and presentation of collective learner behaviour designed to create a feedback loop informing learners of successful paths towards the attainment of learning goals. The approach is presented as an alternative to methods of achieving adaptation in hypermedia-based learning environments which involve learner modelling. The article concludes with a discussion of the questions being addressed in our ongoing research.
\end{abstract}

Keywords: lifelong learning, self-directed learning, navigation, log file analysis 


\section{Introduction}

Lifelong learning refers to the activities people perform throughout their lives to improve their knowledge, skills and competence in a particular field, given some personal, societal or employment related motives (Field, 2001). The European Commission has designated lifelong learning as one of its priorities, identified targets for lifelong learning in Europe, and is monitoring the implementation of strategies in its member states (European Commission, 2003).

Candy (1991) defines a number of characteristics of lifelong education, including its dependence on learners' ability and motivation to engage in self-directed learning activities, which is seen as both a means and an end. Brocket and Hiemstra (1991) define learner self-direction as the learner's assumption of "primary responsibility for and control over decisions about planning, implementing and evaluating the learning experience" and Hiemstra (1994) notes learners' preference to take on responsibility for their own learning.

However, taking on new responsibilities is not without its challenges. Brookfield (1985) notes that although self-directed learning "has connotations of autonomy, independence and isolation", investigations have highlighted that "adults would like more, rather than less, assistance in their learning pursuits". Similarly, Candy (1991) writes that self-directed learners are often challenged to assume certain responsibilities, and that when deciding how to approach learning tasks, the self-directed learner is "confronted with the problem of how to find a way into and through a body of knowledge that is unknown at the outset. Without the benefit of any explicit guidance, a self-directed learner is obliged to map out a course of inquiry that seems appropriate, but that may involve a certain amount of difficulty and disappointment that could have been averted."

Candy's description calls to mind the image of the lifelong learner as navigator, charting a course through educational waters, following Darken and Silbert's (1993) definition of navigation as the "process of determining a path to be traveled by any object through any environment". In subsequent work, Darken (2002) uses the term 'wayfinding' to refer more specifically to the navigator's decision making process.

We use the term "Educational wayfinding" to describe the cognitive, decision-making process carried out by self-directed learners as they assume responsibility for choosing and sequencing their learning events. The wayfinding decisions with which learners are faced arise from the freedom offered to them by learning providers on their way to the attainment of particular goals. In some highly constrained situations, both the choice of learning events and their ordering may be fixed by a learning provider. More likely, learners may be permitted to select and order modules, perhaps to accumulate credit points towards a certificate. In this context, we note Yorke's (1999) warning that "as the unitization of curricula spreads through higher education, so there is a need for greater guidance for students to navigate their way through the schemes".

This leads to the central hypothesis of this paper: difficulties in the educational wayfinding process can lead to learners not reaching their goals, or taking unduly long to do so. The consequences of these difficulties impact the efficiency of education provision - the ratio of output to input (Rumble, 1997) —and can have consequences for providers' direct funding and market image. While there are a large number of factors which can contribute to persistence rates in education (Cookson, 1990; Martinez, 2003; Xenos, Pierrakeas, \& Pintelas, 2002), many of which are beyond the control of learning providers, it would seem to make financial sense for learning providers to try to remove wayfinding problems from the learner retention equation.

Drawing on the above literature, our starting point is that self-directed learners can benefit from support in the educational wayfinding process, and that it is in the interests of learning providers to deliver such support. The purpose of this paper is to describe a new approach to supporting the educational 
wayfinding process which has the potential to address the drawbacks of existing approaches found in the literature. The next section examines a number of alternatives to the provision of such support, and is followed by a section which introduces our approach to issue, building on self-organisation theory. The article concludes with a description of the research questions to be answered in our ongoing work, together with a number of discussion points raised by the approach.

\section{Wayfinding support for lifelong learners}

In examining wayfinding support for lifelong learners, it is instructive to review approaches used today in open \& distance learning (ODL) and also those identified by ODL research but not yet widely implemented.

The first approach involves designing for lifelong learning, creating curricula or content plans to be followed by learners. However, this pre-planning conflicts with the goal of facilitating self-direction, and Evans (1994) notes that the didactic models used in open and distance education are often "founded on highly didactic models which provide [the students] with little control over their own learning ... and the students are left with little option but to adhere to the curriculum". Indeed the ability to predict effective curricula for self-directed learners is called into doubt by Spear and Mocker (1984), who note that learners "tend to select a course from limited alternatives which occur fortuitously within their environment". These reservations suggest the need for a flexible, adaptive approach to wayfinding support, able to respond to learners' changing situations and goals.

Such flexibility can be realised through so-called "learner support services" (Simpson, 2000). LudwigHardman and Dunlap (2003) describe a number of services designed to support learners' self-direction including intake interviews, pre-assessments and one-on-one advising, and other authors have commented on their importance in delivering high quality ODL (LaPadula, 2003; Scheer \& Lockee, 2003). Although capable of providing highly individualised advice, learner support services do not come without a price. Costs are likely to be variable with student numbers and be exacerbated by the less predictable, demand driven nature of lifelong learning. A recent OECD report (2003) comments that lifelong learning "complicates the resource challenge because it changes so many parameters at once ... the substantive content of lifelong learning is defined by the demand of individual learners, [and] the cost of lifelong learning is different because the timing, duration, and venue of lifelong learning are different from those of initial formal education and training".

As a response to this issues of financing support for lifelong learners, a significant amount of research has explored the application of information technologies to lifelong learning support (Dicheva \& McLoughlin, 2003; Sinitsa, 2000). Much of this research revolves around the use of the World Wide Web in lifelong learning, facilitating the creation of distributed networks of learning resources (Zahariadis \& Voliotis, 2003). These educational hypermedia systems (De Bra, 2002) are part of the Adaptive Hypermedia research area (Brusilovsky, 2001; Cristea \& De Bra, 2002). The authors of a recent CEDEFOP thematic workshop report (CEDEFOP, 2003) contend that Adaptive Hypermedia Systems (AHSs) are "particularly suited to implementing lifelong learning ... because they can tailor the learning environment and content to each individual learner's needs and aptitudes".

AHS continues a research line established in the eighties by work in the area of Intelligent Tutoring Systems, in seeking to "build a model of the goals, preferences and knowledge of the individual user and use this through the interaction for adaptation of the hypertext to the needs of the user" (De Bra, Brusilovsky, \& Houben, 1999).

This reliance on accurate, detailed and up-to-date user models is both the theoretical strength of Adaptive Hypermedia and its practical Achilles heel. Without models, or with incorrect ones, adaptation falters. Self (1987), writing over 15 years ago, noted the absence of a theory of learning which might be used to maintain learner models. In a later article (1990), Self describes the scope of the student modelling problem-"from computational questions, to representational issues, through plan recognition, mental 
models, episodic memory to individual differences - to encompass, it would seem, almost all of cognitive science". Although Self has continued to argue for the importance of user models, concerns on its practical application have continued to be raised (Atif, Benlamri, \& J., 2003; Kay, 2001; Strachan, Anderson, Sneesby, \& Evans, 1997). This is perhaps even more problematic in the context of lifelong learning, where goals, preferences and knowledge change with the many and varied family, career and lifestyle influences over a learner's life. Indeed, personalised learning environments based on lifelong learner models were recently described (Hall, 2002) as one of the Grand Challenges for Computing Research, not feasible in a ten to fifteen year timescale, alongside Interfacing with the Human Brain and Getting Androids to Learn from Testimony.

These observations on wayfinding support for lifelong learners raise a question for research in education and information technology: Is there a alternative approach to wayfinding guidance for lifelong learners which might provide a cost-effective solution yet which does not rely upon learner modelling?

\section{Self-organisation and wayfinding}

The previous section reviewed three sources of wayfinding support-course designers, attempting to predict efficient paths for lifelong learners, learner support services, providing flexible advice but at price, and adaptive hypermedia systems, still challenged to prove their practical application. A fourth source can be found in the "other learners", a point noted by Brookfield (1985) when he states that the "successful self-directed learners ... place their learning within a social setting in which the advice, information, and skill modelling provided by other learners are crucial conditions for successful learning". This observation finds echoes in the information navigation literature, where the term social navigation (Höök \& Benyon, 2003) has been coined to describe research reflecting the fact that "navigation is a social and frequently a collaborative process" (Dieberger, 2003). This point is also made by Forsberg et al. (1998) who state that "most information navigation in the real world is performed through talking to other people". However, we need to question whether lifelong learners could solve the wayfinding problem by talking to each other, since this adds an additional burden - that of interacting with others in advice-giving dialogues-to those often already under pressure to combine learning, working and family life.

In fact, social navigation does not always involve direct interaction. The field has been divided into two areas of research. The first, direct social navigation, sees actors as "co-present and in direct contact with one another" (Dieberger, Höök, Svensson, \& Lönnqvist, 2001). In contrast, indirect social navigation exploits traces of interactions left by others (Shipman et al., 1996; Wexelblat, 1999). Applications of indirect social navigation can be found in the educational literature (Shipman, Furuta, Brenner, Chung, \& Hsieh, 2000; Zeiliger, Reggers, Baldewyns, \& Jans, 1997), although the focus has tended to fall on teachers or students pre-defining trails through information space for others to follow later. This approach brings with it a certain cost to the lifelong learner who may not be disposed to investing time and effort to create a trail for unknown learners coming along later. The ideal approach would avoid anyone preplanning wayfinding guides and have them somehow "emerge" so that learning events, as it were, spontaneously acquire (sequential) structures or organisations. This is the language of selforganisation- "the spontaneous formation of well-organised structures, patterns or behaviours, from random initial conditions" (Soraya Kouadri et al., 2003). Indeed the "acquiring of spatial, temporal or functional structure" is seen as the essence of self-organisation by Hadeli et al.(2003), and is echoed by Heylighen and Gershenson (2003) - "a self-organizing system not only regulates or adapts its behavior, it creates its own organization. In that respect it differs fundamentally from our present systems, which are created by their designer."

Bonabeau, Dorigo and Theraulaz (1999) give ant foraging trails as an example of the spatiotemporal structures which emerge as a result of self-organisation. The ability of ants to find efficient (i.e. short) routes between nests and food sources suggests an approach to cost-effective, flexible and implementable wayfinding support. Paths identified by ants are not pre-planned, but emerge, spontaneously, as a result of indirect communication between members of an ant colony-a form of indirect social navigation. Dorigo and Di Caro (1999) describe how ants deposit a chemical substance 
known as pheromone which can be sensed by other ants. When a navigational decision has to be made, such as taking a left branch or a right one, ants make a probabilistic choice based on the amount of pheromone they smell on the branches. Initially, in the absence of deposited pheromone, each of the branches is chosen with equal probability. However, if one branch leads to food faster than the other, ants on their way back will select the shorter branch due to the presence of the pheromone they deposited on the forward journey. More pheromone is deposited, leading to more ants selecting the shortest path, and so on, creating a feedback loop which leads ants along efficient paths to their destination. This process of indirect communication exploited by members of ant colonies is known as stigmergy. In their overview article Theraulaz and Bonabeau (1999) state, "The basic principle of stigmergy is extremely simple: Traces left and modifications made by individuals in their environment may feed back on them.... Individuals do interact to achieve coordination, but they interact indirectly, so that each insect taken separately does not seem to be involved in coordinated, collective behavior". Stigmergy, self-organisation and ant-colony algorithms are the subject of much interest in the computer science community (Di Caro \& Dorigo, 1998; Dorigo, Bonabeau, \& Theraulaz, 2000; Schoonderwoerd, Holland, Bruten, \& Rothkrantz, 1996), for optimisation and routing problems. The application of stigmergy is also being explored in the elearning domain (Dron, 2002; Dron, Boyne, \& Mitchell, 2001), albeit not in the area of wayfinding support.

In the educational arena, efficient paths are not defined in terms of distance, but rather time. We can imagine learners' interactions with learning resources and activities being recorded automatically as they progress through a body of knowledge. The time-stamping of these interactions allows sequences to be identified which can be processed and aggregated to derive a given "pheromone strength" favouring paths which are faster to complete. This information can be fed back to other lifelong learners, providing a new source of navigational guidance indicating "good" ways through the body of knowledge-a selforganising, stigmergic approach to wayfinding support. Such an approach seems to provide an answer to lifelong learning's need in this area. It is cost-effective, since trail creation occurs unnoticed as a side effect of learner interaction with e-learning systems, it is flexible, able to emerge from and adapt to different circumstances, and holds the prospect of being implementable, since its adaptivity (following the definition used by (Cristea \& De Bra, 2002)) does not depend upon learner modelling. Indeed, such an approach abstracts entirely from the characteristics of individual learners, relying instead on the collective behaviour of the swarm of lifelong learners to identify efficient paths.

The next section introduces an architecture which supports the feeding back of collective learner behaviour to support learners in reaching their educational goals efficiently.

\section{An architecture for wayfinding support in lifelong learning}

Our work on wayfinding support is being carried out within the context of a larger R\&D programme, designed to help the creation of flexible lifelong learning facilities that meet the needs of learners at various levels of competence throughout their lives. We refer to these network facilities for lifelong learners as "Learning Networks" or LNs (Koper et al., 2004). Learning networks support seamless, ubiquitous access to learning facilities at work, at home and in schools and universities. We can view a Learning Network as a graph of nodes in a disciplinary domain. The nodes of the graph represent the available learning events, called Activity Nodes (ANs). An AN can be anything that is available to support learning, such as a course, a workshop, a conference, a lesson, an internet learning resource, etc. Providers and learners can create new ANs, can adapt existing ANs or can delete ANs. An LN typically represents a large and ever-changing set of ANs that provide learning opportunities for lifelong learners ("actors") from different providers, at different levels of expertise within the specific disciplinary domain.

Wayfinding support in LNs relies on the following two core concepts:

- The Learner's Position, defined as the set of ANs viewed as completed in the LN. This covers ANs which have actually been completed and those which can be considered as completed, perhaps as a result of exemptions arising from previous study or work experience. This distinction reflects what Spear terms acquired vs. residual knowledge (Spear, 1988). 
- A Learner Target is any set of ANs that is sufficient to reach a particular level of competence or expertise in the domain. These targets and their connected competency levels maybe selfdefined or predefined in the network.

These two concepts equate to "you are here" (position) and "there's where I want to be" (target), and the wayfinding guidance which is fed back concerns effective ways of getting from here to there, based on the behaviour of previous learners.

The architecture we propose combines elements which record, collect, process and present collective lifelong learner behaviour. Andersson et al. (2002) use the phrase Emergent Interaction Systems to describe systems which "consist of an environment in which a number of individual actors share some experience/phenomenon. Data originating from the actors and their behaviour is collected, transformed and fed back into the environment. The defining requirement of emergent interaction is that this feedback has some noticeable and interesting effect on the behaviour of the individuals and the collective - that something 'emerges' in the interactions between the individuals, the collective, and the shared phenomenon as a result of introducing the feedback mechanism. The immediate effect may be enhancement of the individual experience - with resulting effects on the individual's behaviour, choice of action, and so on."

The 'something that emerges' in our situation are paths through bodies of knowledge, rather like wellworn footpaths in forests. Our initial focus is on efficient paths, that is, those which minimise the time taken to reach a certain target from a particular position. Subsequent research will investigate attractive paths, those rated highest by other learners, in line with work on recommender systems (Herlocker, Konstan, Terveen, \& Riedl, 2004; Resnick \& Varian, 1997). Today, neither efficient nor attractive paths are visible to lifelong learners since there are no mechanisms available to reveal them. However, many of the required elements are in place.

Central to the approach are logs of learner information indicating what learners did and when. The use of internet technologies in e-learning has brought with it an increase in the level of standardisation of transmission protocols and data, and logging information is no exception. The World Wide Web Consortium has defined Common and Extended Log File Formats (World Wide Web Consortium, 1996) and a whole area of research is now dedicated to the processing and analysis of these files for various purposes, known as Web Usage Mining (Punin, Krishnamoorthy, \& Zaki, 2001; Spiliopoulou, Pohle, \& Faulstich, 1999; Srivastava, Cooley, Deshpande, \& Tan, 2000). The techniques have also been applied in education (Sheard, Ceddia, \& Hurst, 2003; Zaïane, 2001).

However, the events which are registered in these logs are extremely low level, especially when seen from the lifelong learning perspective. This complicates their analysis, making it difficult to know which users are interacting (since only IP addresses are logged) and what they are doing (since only cryptic Uniform Resource Locators (URLs) are logged). Oberle et al. (2003) note that "an interpretation of URLs in terms of user behaviour, interests and intentions is not always straightforward ... web usage analysis is not interested in patterns of URLs but rather in patterns of application events". The route to solving this problem taken by Oberle et al. is to enhance the logs with additional information drawn from a formal ontology. However, the characteristics of our domain suggest a different type of log is more appropriate, one at a higher level of application event and which records not only which lifelong learner did what, but also whether or not this was successful (eg by including the results of an assessment).

Such a level of logging is available in the learner records data store described in the IEEE Draft Standard for Learning Technology — Learning Technology Systems Architecture (IEEE, 2001). This data store, specifically designed to cater for the nomadic nature of lifelong learners, is defined as a repository of "learner information, such as performance, preference, and other types of information. The learner records may store/retrieve information about the past (e.g., historical learner records), but may also hold information about the present (e.g., current assessments for suspending and resuming sessions) and the future (e.g., pedagogy, learner, or employer objectives)". While the exact format of a learner record is not described in the IEEE draft, the IMS Simple Sequencing Tracking Model (IMSSS, 2003) suggests the 


\section{PRE-PRINT:}

type of information which might be stored when tracking learner interaction with Units of Learning as defined in the IMS Learning Design specification (IMSLD, 2003).

Using this combination of Learning Technology standards \& specifications yields a log from which macro progress (Simpson, 2000) can be derived. Moreover, the use of standards \& specifications helps address the cradle-to-the-grave data management challenge posed by lifelong learning.

With the notions of position, target and learner record in place, the elements of an architecture for selforganising wayfinding support for lifelong learners can be introduced (Figure 1).

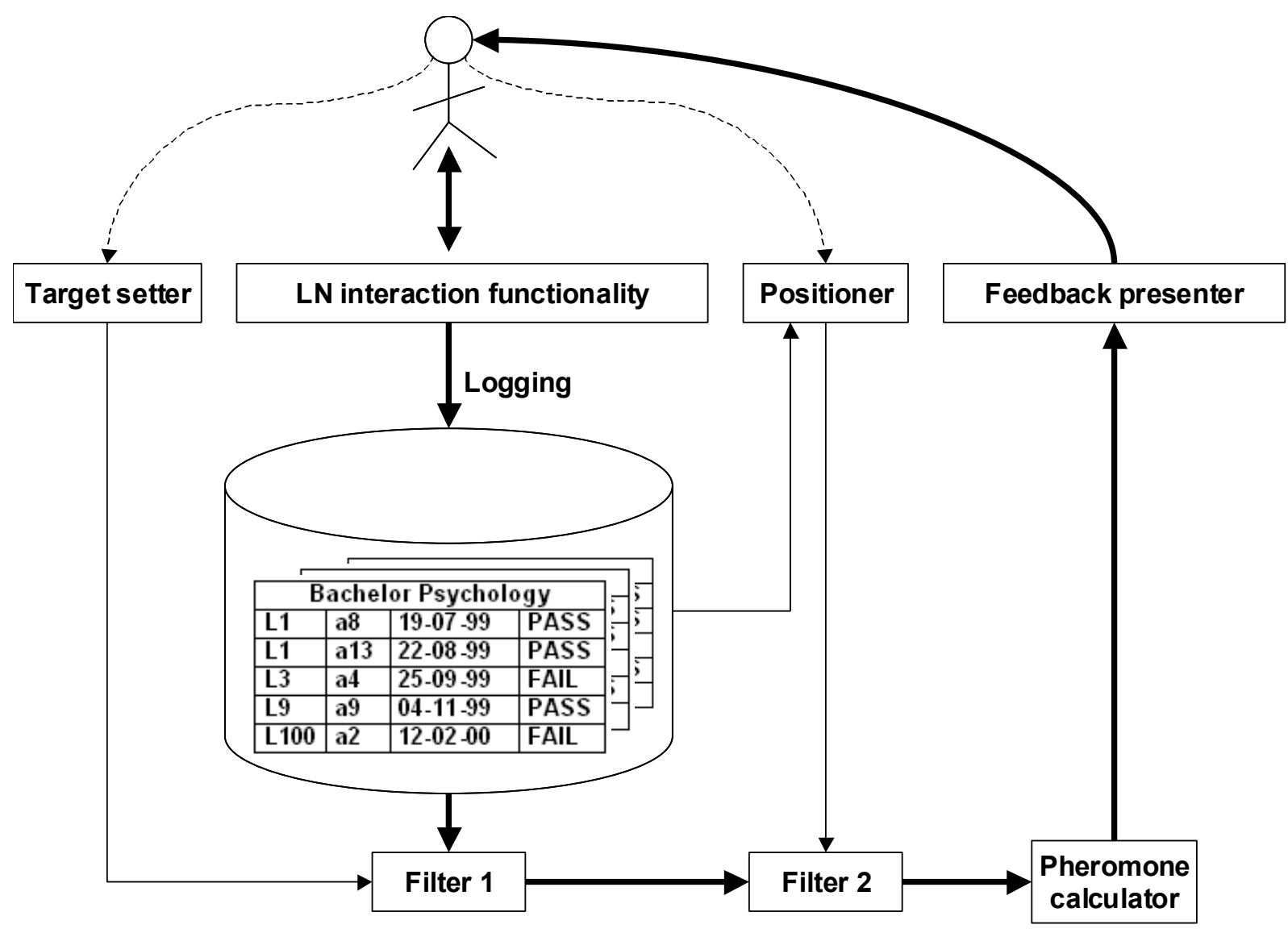

Figure 1. An architecture for wayfinding support for lifelong learners

Lifelong learners interact with the functionality available in a learning network (Koper et al., 2004). Learner-Activity Node interaction is logged in a Learner Record Store along the lines described above, including information on the learner, the AN, a timestamp and an indication of performance (for example, pass or fail). The lifelong learner has access to a Feedback Presenter which reveals how other learners with the same target and from the same position have successfully progressed to their (shared) target. This information is derived from the collective log of learner interactions, following both filtering and processing.

The filtering is used first to limit the feedback to involve only those learner-AN interactions on the way to the same target as the learner (in Figure 1, Filter 1), ensuring that any guidance is directing the learner appropriately. Filter 1 assumes some mechanism by which a lifelong learner's target(s) can be set and updated (the Targetsetter). Although we may speculate on advanced systems able to infer goals by examining the learner record store, a more practical approach may be to have the learner indicate 
PRE-PRINT:

target(s) from a set of competency levels achievable in a given learning network. This is in line with Self's (1990) advice: Avoid Guessing: get the student to tell you what you need to know.

Once the dataset has been reduced to focus on other lifelong learners with the same target, a second filter is applied (in Figure 1, Filter 2) to reduce it further to those learners who have departed from the same position as the learner ("others with your target and position proceeded as follows"). This second filter also assumes a mechanism is assumed which maintains the learner's position in a learning network (the Positioner).

The processing is used to calculate a "pheromone" value for the various next steps taken by other learners, favouring the step taking the least time to complete. The next steps can be ranked on the basis of pheromone strength and revealed to the learner via the Feedback Presenter.

With this architecture in place, lifelong learners are given access to information hitherto unavailable to them, yet of importance to the wayfinding process. The learner is able to find answers to questions such as "How did other learners progress in this learning network from where I am now?", "Which path through the learning network offer the most chance of success?" and "What has been the most efficient (i.e. fastest) path taken by others through this Learning Network?".

\section{Discussion}

This paper has described the rationale behind our research into self-organising wayfinding support, and described an architecture for its provision. Our approach is designed to adapt support for decisions on the sequencing of learning events not on the basis of a model of the individual learner but using information on the collective behaviour of other learners.

We are currently analysing learner record information covering the many thousands of lifelong learners studying at our institution. This analysis will inform the central research questions for our work: Which information should be fed back to learners (eg time to reach target)? How should information be revealed (eg as a list of alternative next steps or as a weighted map of the learning network)? When should feedback be given (should a threshold of interaction be reached before the feedback becomes active for learners)? How should the benefit of the introduction of the feedback be measured?

Once our analysis is complete, we intend to simulate the introduction of an educational technology implementing the feedback loop to predict the impact of its introduction before carrying out experiments with lifelong learners to measure the actual value of the approach with an implemented tool.

In conclusion, we underline three important aspects of our work:

- The work is intended to open a new source of information to help lifelong learners in deciding how to progress towards their learning goals. This source (others with shared positions and targets) is a natural one in the world of social navigation but is today unavailable to lifelong learners.

- The envisaged feedback loop has an advisory character, and is not intended to push all learners down a single path as quickly as possible. There are many influences on lifelong learners' decisions to pursue, continue, stop or suspend a course of learning and the freedom of choice rests with the lifelong learner. Our approach is designed to allow lifelong learners to make informed choices concerning steps on their learning journey, based on actual rather than predicted learner behaviour.

- The approach does not equate lifelong learners with ants and thereby preclude individual complexity. Rather, it seeks to abstract away from the complexity of learning processes and motivations in individuals to the level of learner-AN interaction. This follows Bonabeau, Dorigo 
PRE-PRINT:

and Theraulaz's (1999) view that "at some level of description it is possible to explain complex collective behaviour by assuming that insects are relatively simple interacting entities".

Our work is still in its initial phases; subsequent articles will report on the methods and techniques used in the research, together with the results of its evaluation.

\section{Acknowledgements}

The authors would like to thank Wim Waterink and Catherine Bolman of the Psychology Department, and Pierre Höppener of the Marketing department, at The Open University of The Netherlands for their contributions to this work.

\section{References}

Andersson, N., Broberg, A., Bränberg, A., Janlert, L.-E., Jonsson, E., Holmlund, K., et al. (2002). Emergent Interaction - A Pre-study, . Umeå: Department Of Computing Science, Umeå University,.

Atif, Y., Benlamri, R., \& J., B. (2003). Learning Objects Based Framework for Self-Adaptive Learning. Education and Information Technologies, 8(3), 345-368.

Bonabeau, E., Dorigo, M., \& Theraulaz, G. (1999). Introduction. In M. D. G. T. E. Bonabeau (Ed.), Swarm Intelligence. Oxford: Oxford University Press.

Brockett, R. G., \& Hiemstra, R. (1991). Self-direction in adult learning: Perspectives on theory, research, and practice. London: Routledge.

Brookfield, S. (1985). Self-Directed Learning: A Critical Review of Research. In S. Brookfield (Ed.), SelfDirected Learning: From Theory to Practice (Vol. 25). San Francisco: Jossey-Bass Inc.

Brusilovsky, P. (2001). Adaptive Hypermedia. User Modeling and User-Adapted Interaction, 11, 87-110.

Candy, P. C. (1991). Self-Direction for Lifelong Learning. San Franciso: Jossey-Bass Inc.

CEDEFOP. (2003). Adaptive Hypermedia - its role in lifelong learning. Retrieved March 19th, 2004, from http://www.trainingvillage.gr/etv/HomePages/Front page news/LLL03/AdaptiveHypermedia.pdf

Cookson, P. S. (1990). Persistence in Distance Education: A Review. In M. G. Moore (Ed.), Contemporary Issues in American Distance Education (pp. 192-204). Oxford: Pergamon Press.

Cristea, A., \& De Bra, P. (2002). ODL Education Environments based on Adaptivity and Adaptability. Paper presented at the World Conference on E-Learning in Corp., Govt., Health., \& Higher Ed. (ELEARN), Montreal.

Darken, R. P., \& Peterson, B. (2002). Spatial Orientation, Wayfinding, and Representation. In K. M. Stanney (Ed.), Handbook of Virtual Environments: Design, Implementation, and Applications. New Jersey: Lawrence Erlbaum Assoc.

Darken, R. P., \& Silbert, J. L. (1993). A Toolset for Navigation in Virtual Environments. Paper presented at the ACM User Interface Software \& Technology.

De Bra, P. (2002). The Adaptive Web - Adaptive Educational Hypermedia on the Web. Communications of the Association for Computing Machinery, 45(5), 60-61.

De Bra, P., Brusilovsky, P., \& Houben, G.-J. (1999). Adaptive Hypermedia: From Systems to Framework. ACM Computing Surveys, 31(4).

Di Caro, G., \& Dorigo, M. (1998). AntNet: Distributed stigmergic control for communications networks. Journal of Artificial Intelligence Research, 9, 317-365.

Dicheva, D., \& McLoughlin, C. (2003). Special Issue Editorial: Web-based educational environments for lifelong learning. International Journal of Continuing Engineering Education and Lifelong Learning, 13(1/2).

Dieberger, A. (2003). Social Connotations of Space in the Design for Virtual Communities and Social Navigation. In K. H. D.Benyon (Ed.), Designing Information Spaces : The Social Navigation Approach, . London: Springer.

Dieberger, A., Höök, K., Svensson, M., \& Lönnqvist, P. (2001). Social Navigation Research Agenda. 
PRE-PRINT:

Paper presented at the CHI'01, Seattle.

Dorigo, M., Bonabeau, E., \& Theraulaz, G. (2000). Ant algorithms and stigmergy. Future Generation Computer Systems, 16, 851-871.

Dorigo, M., \& Di Caro, G. (1999). The Ant Colony Optimization Meta-Heuristic. In D. Corne, M. Dorigo \& F. Glover (Eds.), New Ideas in Optimization (pp. 11-32). London: McGraw-Hill.

Dron, J. (2002). Achieving self-organization in network-based learning environments. Unpublished Ph.D., University of Brighton, Brighton.

Dron, J., Boyne, C., \& Mitchell, R. (2001). Footpaths in the Stuff Swamp. Paper presented at the Proceedings of WebNet 2001, Orlando, Florida.

European Commission. (2003, 17.12.2003). Implementing lifelong learning strategies in Europe: Progress report on the follow-up to the Council resolution of 2002. Retrieved March 11th, 2004, from http://europa.eu.int/comm/education/policies/2010/doc/synthesis efta eea en.pdf

Evans, T. (1994). Understanding Learners in Open and Distance Education. London: Kogan Page.

Field, J. (2001). Lifelong education. International Journal of Lifelong Education, 20(1/2), 3-15.

Forsberg, M., Höök, K., \& Svensson, M. (1998). Design Principles For Social Navigation Tools. Paper presented at the Proceedings of the 4th ERCIM Workshop on 'User Interfaces for All', Special Theme 'Towards an Accessible Web', Stockholm.

Hadeli, P. V., Zamfirescu, C. B., Van Brussel, H., Saint Germain, B., Holvoet, T., \& Steegmans, E. (2003). Self-Organising in Multi-agent Coordination and Control Using Stigmergy. Paper presented at the The First Workshop on Self-Organising Engineering Applications (ESOA 2003), Melbourne, Australia.

Hall, W. (2002). Grand Challenge: Lifelong e-Learning. Retrieved April 1st, 2004, from http://www.nesc.ac.uk/esi/events/Grand Challenges/panelc/c6.pdf

Herlocker, J. L., Konstan, J. A., Terveen, L. G., \& Riedl, J. T. (2004). Evaluating collaborative filtering recommender systems. ACM Transactions on Information Systems (TOIS), 22(1), 5-53.

Heylighen, F., \& Gershenson, C. (2003). The Meaning of Self-organization in Computing. IEEE Intelligent Systems, section Trends \& Controversies - Self-organization and Information Systems, May/June.

Hiemstra, R. (1994). Helping Learners Take Responsibility for Self-Directed Activities. In R. Hiemstra \& R. G. Brockett (Eds.), Overcoming Resistance to Self-Direction in Adult Learning (Vol. 64, pp. 8187). San Franciso: Jossey-Bass Inc.

Höök, K., \& Benyon, D. (2003). Designing Information Spaces : The Social Navigation Approach. London: Springer.

IEEE. (2001). IEEE Draft Standard for Learning Technology - Learning Technology Systems Architecture. Retrieved March 26th, 2004, from Itsc.ieee.org/wg1/files/IEEE_1484_01_D08_LTSA.pdf

IMSLD. (2003). IMS Learning Design Specification. Retrieved February 27 th, 2004, from http://www.imsglobal.org/learningdesign/index.cfm

IMSSS. (2003). IMS Simple Sequencing Specification. Retrieved March 27th, 2004, from http://www.imsglobal.org/simplesequencing/index.cfm

Kay, J. (2001). Learner Control. User Modeling and User-Adapted Interaction, 11(1-2), 111-127.

Koper, E. J. R., Giesbers, B., Van Rosmalen, P., Sloep, P., Van Bruggen, J., Tattersall, C., et al. (2004). A Design Model for Lifelong Learning Networks. Interactive Learning Environments, (in press).

LaPadula, M. (2003). A Comprehensive Look at Online Student Support Services for Distance Learners. American Journal of Distance Education, 17(3), 119-129.

Ludwig-Hardman, S., \& Dunlap, J. C. (2003). Learner Support Services for Online Students: Scaffolding for Success. International Review of Research in Open and Distance Learning, 4(1).

Martinez, M. (2003). High Attrition Rates in e-Learning: Challenges, Predictors, and Solutions. The eLearning Developers' Journal, July.

Oberle, D., Berendt, B., Hotho, A., \& Gonzalez, J. (2003). Conceptual user tracking. In J. S. E.M. Ruiz, \& P.S. Szczepaniak (Ed.), Web Intelligence, First International Atlantic Web Intelligence Conference (AWIC 2003). Berlin: Springer,.

OECD. (2003). A Systemic Approach to Co-Financing Lifelong Learning. Paper presented at the "Policies to strengthen incentives and mechanisms for co-financing lifelong learning", Bonn.

Punin, J. R., Krishnamoorthy, M. S., \& Zaki, M. J. (2001). Web Usage Mining: Languages and Algorithms. In Studies in Classification, Data Analysis, and Knowledge Organization: Springer-Verlag. 
PRE-PRINT:

Resnick, P., \& Varian, H. R. (1997). Recommender Systems. Communications of the ACM, 40(3), 56-58. Rumble, G. (1997). The Costs and Economics of Open and Distance Learning. London: Kogan Page.

Scheer, S. B., \& Lockee, B. B. (2003). Addressing the Wellness Needs of Online Distance Learners. Open Learning, 18(2), 177-196.

Schoonderwoerd, R., Holland, O. E., Bruten, J. L., \& Rothkrantz, L. J. M. (1996). Ant-Based Load Balancing in Telecommunications Networks. Adaptive Behavior(2), 169-207.

Self, J. (1987). User Modelling in Open Learning Systems. In J. Whiting \& D. A. Bell (Eds.), Tutoring and Monitoring Facilities for European Open Learning. Amsterdam: Elsevier.

Self, J. (1990). Bypassing the Intractable Problem of Student Modelling. In C. F. a. G. Gauthier (Ed.), Intelligent Tutoring Systems: at the Crossroads of Artificial Intelligence and Education. Norwood: Ablex.

Sheard, J., Ceddia, J., \& Hurst, J. (2003). Inferring Student Learning Behaviour from Website Interaction: A Usage Analysis. Education and Information Technologies, 8(3), 245-266.

Shipman, F., Furuta, R., Brenner, D., Chung, C., \& Hsieh, H. (2000). Guided Paths through Web-Based Collections: Design, Experiences, and Adaptations. Journal of the American Society of Information Sciences, 51(3), 260-272.

Shipman, F., Marshall, C., Furuta, R., Brenner, D., Wei, H., \& Kumar, V. (1996). Creating educational guided paths over the world-wide web. Paper presented at the ED-TELECOM, Boston.

Simpson, O. (2000). Supporting students in online, open and distance learning. London: Kogan Page.

Sinitsa, K. (2000). Learning Individually : a Life-Long Perspective Introduction to the Special Issue. Educational Technology \& Society, 3(1).

Soraya Kouadri, M., Rana, O. F., Foukia, N., Hassas, S., Giavanna Di Marzo, S., Van Aart, C., et al. (2003). Self-Organizing Applications: A Survey. Paper presented at the Engineering SelfOrganising Applications, First International Workshop, ESOA 2003. Melbourne, Victoria, Melbourne, Australia.

Spear, G. E. (1988). Beyond the organizing circumstances: A search for methodology for the study of self-directed learning. In H. B. Long, \& Associates (Ed.), Self-directed learning: Application \& theory. Athens, GA: University of Georgia.

Spear, G. E., \& Mocker, D. W. (1984). The Organizing Circumstance: Environmental Determinants in Self-Directed Learning. Adult Education Quarterly, 35(1), 1-10.

Spiliopoulou, M., Pohle, C., \& Faulstich, L. C. (1999). Improving the effectiveness of a web site with web usage mining. Paper presented at the Proc. of KDD Workshop WEBKDD'99.

Srivastava, J., Cooley, R., Deshpande, M., \& Tan, P. (2000). Web Usage Mining: Discovery and Applications of Usage Patterns from Web Data. SIGKDD Explorations,, 1(2).

Strachan, L., Anderson, J., Sneesby, M., \& Evans, M. (1997). Pragmatic User Modelling in a Commercial Software System. Paper presented at the User Modeling: Proceedings of the Sixth International Conference, UM97, Sardinia.

Theraulaz, G., \& Bonabeau, E. (1999). A Brief History of Stimergy. Artificial Life, 5(2), 97-116.

Wexelblat, A. I. p. (1999). Footprints: History-Rich Tools for Information Foraging. Paper presented at the Proceedings of Conference on Human Factors in Computing Systems (CHI'99), Pittsburgh.

World Wide Web Consortium. (1996). Extended Log File Format. Retrieved March 26th, 2004, from http://www.w3.org/TR/WD-logfile

Xenos, M., Pierrakeas, C., \& Pintelas, P. (2002). A survey on student dropout rates and dropout causes concerning the students in the Course of Informatics of the Hellenic Open University. Computers \& Education, 39, 361-377.

Yorke, M. (1999). Leaving Early. Undergraduate Non-completion in Higher Education. London: Falmer Press.

Zahariadis, T., \& Voliotis, S. (2003). New Trends in Distance Learning Utilising Next Generation Multimedia Networks. Education and Information Technologies, 8(1), 67-81.

Zaïane, O. R. (2001). Web Usage Mining for a Better Web-Based Learning Environment. Paper presented at the Proc. of Conference on Advanced Technology for Education, Banff, Alberta.

Zeiliger, R., Reggers, T., Baldewyns, L., \& Jans, V. (1997). Facilitating Web Navigation : Integrated tools for Active and Cooperative Learners. Paper presented at the Proceedings of the 5th International Conference on Computers in Education, ICCE'97, Malaysia. 